\title{
Shadows and light: Diversity Management as Phantasmagoria
}

\author{
Christina Schwabenland, University of Bedfordshire, UK
}

Frances Tomlinson, London Metropolitan University, UK

\begin{abstract}
Within the field of critical diversity studies increasing reference is made to the need for more critically informed research into the practice and implementation of diversity management. This article draws on an action research project that involved diversity practitioners from within the UK voluntary sector. In their accounts of resistance, reluctance and a lack of effective organizational engagement, participants shared a perception of diversity management as something difficult to concretize and envisage; and as something that organizational members associated with fear and anxiety; and with an inability to act. We draw on the metaphor of the phantasmagoria as a means to investigate this representation. We conclude with some tentative suggestions for alternative ways of doing diversity.
\end{abstract}

Key words: anxiety, diversity management, phantasmagoria, resistance, voluntary sector

\section{Introduction}

Equality and diversity ... I can give you a definition but I can't actually see it, I'm not actually sure exactly what equality and diversity should look like for our organization [but] I'm aware that we're not doing enough in that area . . (John: a pseudonym)

This observation was made during the first session of an action research project we ran for diversity practitioners working in the UK voluntary (non-profit/non-governmental) sector and was only one of a number of similar observations in which the participants shared a 
perception of diversity management as something they found difficult to concretize. In the example cited above, the uncertainty about what diversity management actually looks like is also associated with anxiety over the lack of progress, of 'not doing enough'. Our previous research (Tomlinson and Schwabenland, 2010) had revealed that even in organizations that make the empowerment of people from marginalized groups central to their mission, actors experience significant and persistent dilemmas in the practice of diversity and equality. In order to gain greater insight into the ways in which practitioners conceptualize and resolve these dilemmas, we convened a facilitated action research group, bringing together practitioners from a range of voluntary sector organizations, to share and reflect on their experiences.

Their perception of diversity management as something intangible and ill-defined was an unexpected finding, one we considered worthy of further exploration and analysis. To guide our analysis, we took up the association that Christina made as she listened to the action research group's sharing of their uncertainties and anxieties. She had written in her notes: 'are these phantasms? This is a phantasmagoria!'. We therefore chose to adopt the phantasmagoria as a metaphor, a lens through which we could focus more clearly on these themes of ambiguity and anxiety, communicated by our diversity practitioners.

The phantasmagoria was originally an 18th century form of entertainment involving the creation of illusory phenomena through the projection and manipulation of light and shadow. It has since been applied by a range of authors as a metaphor with which to surface invisible, unacknowledged or shadowy aspects of modernity and to explore the contents of contemporary social imaginaries. Critical diversity researchers have recognized that diversity management contains within itself numerous contradictions and dilemmas (Litvin, 
1997; Lorbiecki and Jack, 2000; Schwabenland, 2012; Sinclair, 2006; Tomlinson and Schwabenland, 2010; Wrench, 2005); in contrast, the more practitioner- and consultancybased literature tends to present the diversity project as relatively straightforward (Cox and Blake, 1991; Kandola and Fullerton, 2003; Özbilgin et al., 2014). Drawing on the metaphor of the phantasmagoria enabled us to further expose the limitations and implications of modernist, functionalist and managerialist accounts of diversity management - according to which it is inherently doable, uncontroversial and unproblematic, providing that the 'correct' policies and procedures are adequately explained and promulgated. Our analysis involved 'super-naturalizing' the phenomena of diversity; in contrast to the 'naturalizing' of the strange so that it becomes familiar, we are interested in rendering the familiar strange, or uncanny. We do this in order to draw out the practice implications of diversity management's ambiguous, contradictory and contested aspects.

Our concern is specifically with the practitioner experience and with the management of diversity rather than diversity itself. Our approach is informed by both critical and performative approaches; the latter being a response to the call for more research into the practice of diversity management (Zanoni et al., 2010). Specifically, Calàs et al. (2009: 350) suggest that more research is needed into 'the application of managing diversity by social agencies intending to benefit traditionally discriminated populations and the possibly contradictory consequences of using [such] a managerialist approach'. We regard the UK voluntary sector as being a particularly fruitful location for the kind of enquiry that Calàs et al. recommend, noting that current research continues to affirm the importance of the values of equality and inclusion within the sector (Blake et al., 2006; Cairns et al., 2010) and the satisfaction of stakeholder needs in framing accounts of legitimacy (Meyer et al., 2013). 
Discussion of the findings and implications of such research must necessarily take into account the context in which diversity management is practised: we argue against a universalizing and de-contextualized understanding of diversity management; instead, we regard it as always constructed and enacted within very specific political, cultural and societal constraints. Within these constraints, our aim is to develop greater understanding of the emotional experiences that accompany the practice of diversity management; specifically those of confusion, anxiety and fear, which may be particularly hard to articulate within the organizational setting; to investigate the extent to which these experiences are a reflection of contradictions inherent in the diversity project; and to consider whether the acceptance and acknowledgement of these experiences may point to alternative ways of doing diversity. We begin by highlighting the debate found within the current diversity literature between the mainstream and critical approaches. We highlight the potential contribution of the more recent 'gothic turn' in diversity studies in providing a lens through which to explore the shadow side of practitioner experiences. We then discuss the phantasmagoria, both in its original conception and in its use as a metaphor. The subsequent section presents an account of the research process, providing some contextual information about the participants and the particular roles through which diversity management is enacted in the UK. We describe our approach to the facilitation of the group and analysis of the data it generated. We then narrate a representation of diversity management as an unfolding gothic tale, constructed through the application of the metaphor of the phantasmagoria to participants' depictions of their experiences. We next discuss the implications of our analysis for practice and we conclude with a consideration of the strengths and limitations of the phantasmagoria as a heuristic. 


\section{Critical diversity research: From mainstream to gothic}

The apparent consensus, shared by the group at its first meeting, that within their organizations equality and diversity was something difficult to know and recognize seems surprising given the widespread diffusion of literature on the managing of diversity, both practitioner-and research-based, that has taken place since it first emerged in the USA in the late 1980s. As Calàs et al. (2009: 349) put it, 'diversity management has become so ubiquitous as to be unremarkable'. On the other hand, as Tatli (2011) notes, there is a polarization in the diversity literature between mainstream and critical approaches. Mainstream approaches focus on the positive performance-related outcomes of diversity and business case arguments; representing diversity management as a relatively unproblematic and uncontroversial means to unleash creativity and potential (Cox and Blake, 1991; Kandola and Fullerton, 2003; Özbilgin et al., 2014). What was originally a legal and political project of achieving greater equality and combating discrimination has been transformed into a managerial project, in which the pursuit of social justice has become subordinated to the pursuit of business benefits. The promise of managing diversity is the achievement of greater organizational equality and inclusion through the application of management 'tools' and best practice initiatives. For example, Özbilgin et al. (2014), reviewing an impressive array of literature, conclude that these benefits are experienced at the individual level (as higher levels of satisfaction and commitment) and at the team level (as enhanced creativity and more effective decision making) as well as at the organizational level (as improvements in performance, corporate reputation and stakeholder engagement). However, critical scholars claim that the practices recommended in the mainstream HRM literature and good practice guides have not proved effective in achieving greater inclusion or the enhanced organizational participation of disadvantaged groups (Ghorashi and Sabelis, 2013; Janssens and Zanoni, 2014; Wrench, 2005). Ghorashi and Sabelis (2013: 84) argue that the stress on 
economic benefit attached to managing diversity has resulted in it being 'rigid, essentialist and procedurally driven'; while according to Janssens and Zanoni (2014) conventional diversity practices such as training, networking and mentoring are largely focused on influencing individual cognitions and thus fail to engage with structural factors and processes. Individualistic, meritocratic discourses of diversity reinforce, rather than challenge, the existing status quo; installing managers in a privileged position with the power to decide which elements of diversity are, and are not, welcome (Holvino and Kamp, 2009; Janssens and Zanoni, 2005; Sinclair, 2006; Wrench, 2005).

A principal point of tension concerns how diversity discourses engage with questions of sameness and difference. In mainstream accounts, 'diversity attributes' such as gender, ethnicity and age are treated as individual differences on a par with attributes such as personality or work-based preferences or skills (Cox and Blake, 1991; Holvino and Kamp, 2009), which, if managed effectively, add value to the organization. Such differences are rendered as controllable entities (Ahonen et al., 2014); uncontroversial, stable, objective and unambiguous categories. Critical scholars, on the other hand, challenge the normalizing and naturalizing entailed by this treatment of diversity attributes. They argue that such differences should be understood instead as social constructions; fluid, ambiguous, multiple and contradictory, and suffused with political meaning (Bendl et al., 2008; Janssens and Zanoni, 2014; Litvin, 1997; Prasad, 2012). Such an understanding invites questions concerning the consequences (for the erosion or persistence of organizational inequalities) of alternative ways of constructing differences within particular institutional contexts but, as Holvino and Kamp (2009: 398) point out, 'these are not easy questions to answer in the search for corporate quick solutions and fixes'. 
The principal objection that is held by critical scholars towards mainstream diversity management is its lack of engagement with power and context. From a critical perspective, diversity management is understood as contested, multi-layered and problematic; its practice inevitably throws up dilemmas and conflicts. However, it is also argued that since this critique is well established there is now a need to revitalize the field (Ahonen et al., 2014; Calàs et al., 2009; Zanoni et al., 2010). It is proposed that critical diversity researchers should apply a more proactive, performative perspective that is not afraid to consider alternative approaches and solutions to the practice of diversity management (Tatli, 2011; Zanoni et al., 2010), in order to achieve greater insight into 'how organizations can achieve greater equality despite their capitalist nature' (Janssens and Zanoni, 2014: 311). Furthermore, it may be argued that 'more contentious and uncomfortable aspects of workforce diversity' that, according to Dick and Cassell (2002: 973), demand further study, are still neglected in diversity research. The efforts to normalize and naturalize difference that are a feature of mainstream discourse do not only involve neutralizing diversity in a political sense, but in an emotional sense also. The critique of diversity management has focused mainly on its ideological aspects - arguably, both critical and mainstream researchers have neglected the emotional effects of diversity management.

However, the use of gothic tropes to re-frame, or 'super-naturalize' organizational phenomena (Parker, 2005) does serve to focus attention on the shadow side of organizations, and the part played by emotion, fantasy, spontaneity and sickness in organizational life (Gabriel, 2005). Parker suggests that the use of the gothic imagination to inspire social critique has a long tradition, going back at least 200 years, and he cites various, highly influential literary texts to support this claim. However, its appeal to organization theorists is more recent. This body of critically-oriented research invokes a variety of gothic tropes to 
represent that which stands in contrast to ideas of order, control and of organizations as bounded entities. 'Organizational gothic', suggests Parker, 'resist[s] sanitised versions of a brave new world' (Parker, 2005: 153) through 'show[ing] the darkness hiding in the light' (2005: 155). The application of the gothic imagination to research into diversity management is more recent still, although relevant examples include Thanem's appropriation of the 'monstrous' to challenge managerialist diversity discourses, according to which the 'otherness' of monsters can be 'adapted and utilised' for organizational ends (Thanem, 2006: 179) and Riach and Kelly's (2013) work drawing on associations of the vampire in literature and popular culture to reveal the processes through which older workers become positioned as objects to be sacrificed in the interests of organizational immortality, rejuvenation and neophilia. In their analysis, the problematic 'older worker' identity is not something constructed independently of neutral organizational practices and processes; instead, the 'monstrous' organization is itself implicated in the production of the ageing subject. In these examples the gothic is 'a vehicle through which the interrogation and problematizing of mainstream versions of reality and so-called "normal" values is made possible' (Smith and Wallace, 2004: 6) through being rendered uncanny.

In summary, we present our analysis as a response to the call for more critically-inspired research into practitioner experiences, and we specifically note the scarcity of work on the emotional and uncomfortable aspects of diversity management. We suggest that the recent examples of the use of the gothic imagination as an analytical lens in diversity studies offers promising possibilities, while also noticing that here too, much of the work in this vein is primarily theoretical, suggesting a need for more empirically-informed research. Our contribution to this literature is inspired by the association to the phantasmagoria that one of us made during the initial session of the action research group, and in the following section 
we explore its relevance as a metaphorical lens through which to interrogate the more shadowy aspects of diversity management.

\section{The phantasmagoria: A gothic metaphor for the analysis of diversity management}

The original phantasmagoria was invented in France in the late 18th century and was a theatre of shadows in which light effects were projected onto a screen, in the manner of a magic lantern. Although any image could be projected, the actual subject matter of the phantasmagoria tended to draw on contemporary symbols of the uncanny: 'spectral illusion, morbid, frequently macabre, supernatural, fit to inspire terror and dread' (Warner, 2006: 148). Early performances were staged in a ruined convent, and populated with characters drawn from the recent revolution, including Danton, whose severed head was 'projected on to smoke, and then gradually faded away, changing into a skull as it did so' (Warner, 2006: 147).

The earliest phantasmagoria were devised by Etienne-Gaspard Robertson (Cohen, 1989; Warner, 2006). Alongside the fear he hoped to engender (successfully, according to contemporaneous accounts), Robertson also wanted to de-mystify his spectres through exposing the mechanisms by which they were produced, maintaining that 'his illusions were designed as an antidote to superstition and credulity' (Robertson, 1830, cited in Warner, 2006: 153). This simultaneous appeal to the metaphysical and the material is one of the most captivating aspects of the phantasmagoria and has provided the inspiration for its use as a metaphor by authors drawing on psychoanalytic interpretations of social phenomena such as Walter Benjamin in his 1927 book Das Passagen-Werk (usually translated as The Arcades Project) and Marina Warner in her exploration of 'haunted modernity' (Warner, 2006: 152). 
Benjamin and Warner deploy the phantasmagoria in their investigations of the juxtaposition of the scientific rationality of modernity with the "mysteries of the spirit ... the shadows of the mind' (Warner, 2006: 10) and here we find resonances with the debate highlighted above, between the mainstream and critical accounts of diversity management. Warner's interest is in charting contemporaneous manifestations of the spirit that accompany (or shadow) the growth of modernity and rationality as a discordant other that not only refuses to die, but continually reasserts itself with new vitality; Warner might regard Thanem's organizational monsters in this vein.

Benjamin uses the phantasmagoria in his analysis of 19th century Paris as the structuring principle of The Arcades Project. This volume, a montage of fragmented thoughts, records his observations and pictures of city life (Benjamin, 2002; Leslie, undated). Benjamin's recorded intention in The Arcades Project was to create 'a primal history' of the nineteenth century not through conceptual analysis but something akin to dream interpretation ... not the great men and celebrated events of traditional historiography but rather the 'refuse' and 'detritus' of history, the half concealed, variegated traces of the daily life of the 'collective'. (Eiland and McLaughlin, 2002: ix)

The refuse and detritus so captured in his account are the shadowy 'others' of the capitalist project; when considering the more celebratory accounts of diversity management Benjamin's use of the phantasmagoria as a structuring principle asks us to consider what might be half or fully concealed from such accounts.

Reading The Arcades Project was designed to invoke the experience of moving through the Arcades themselves; an experience that Benjamin likened to a phantasmagoria of images of 
fetishized objects; his argument being that under capitalism commodities become transformed into super-naturalized objects of desire. His use of the phantasmagoria, in turn, inspired Burnett's deconstruction of the celebratory, or fetishized discourse applied to virtual organization, which he argues is 'characterised as a mysterious and magical domain' (Burnett, 2013: 15). Burnett regards this discourse as characteristic of much of the corpus of management studies (in that we would include mainstream diversity literature) that highlights the constructive aspects of capitalism and obscures its more destructive characteristics. De Cock et al. (2011) drew on the phantasmagoria as a metaphor in their analysis of images produced by financial companies following the 2008 financial crisis. They constructed a collage from these images that they then used as a heuristic to surface/expose the underlying social imaginary. In their article, De Cock et al. (2011: 167) highlighted the differences between the overt messages of the advertisements, aimed at the general public, and their more covert appeal that was to the financial institutions themselves: 'reflect[ing] back . . . the phantasmal aspects' of these messages - namely, the representation of financial institutions as timeless and immortal. These mythic illusions are intended to reassure rather than to frighten (as are the fetishized commodities of Benjamin's Arcades and Burnett's celebratory discourses); however, in contradistinction to Robertson's original phantasmagoria, it is in the exposure of their inner workings that we encounter their more fearful aspects.

The authors in the examples cited above have drawn on the phantasmagoria as a metaphor in contrasting and overlapping ways. Each has used the metaphor as a mechanism for the exposure, and concomitant resistance to prevailing ideologies whether of modernity (Warner), capitalism (Benjamin, and perhaps also De Cock et al.) or managerialism (Burnett). The metaphor carries out this work either by drawing on a repertoire of characters that have scary or monstrous qualities, or by fetishizing, or super-naturalizing, the ordinary. Benjamin 
and De Cock et al. have appropriated its structure as an assemblage of images in their own constructions of montage and collage, while Warner has drawn on its shadowy and ephemeral qualities to evoke the ghosts of 'haunted modernity'. These examples suggest resonances between the phantasmagoria and the phenomena of diversity management; its emergence alongside, and incorporation within more mainstream managerialist discourses, the fetishizing of those discourses concomitant with the apprehension of more shadowy, partially concealed experiences and meanings; an effluence that resists such celebratory accounts and, finally, the use of the metaphor to surface and give it shape. The phantasmagoria, both as it was originally envisioned by its early progenitors and as subsequently reinterpreted as a metaphorical heuristic, offers a powerful mechanism for exploring contemporary social imaginaries and thus provides an excellent frame through which to interpret and interrogate the experiences of ambiguity and anxiety presented by the diversity practitioners who participated in our study.

\section{An account of the research process}

The research on which we draw engaged managers and practitioners from within the UK voluntary (NGO) sector. Earlier we have suggested that while diversity research is characterized by the debates between the mainstream and critical traditions, the practice of diversity management, especially within the voluntary sector, is also shaped by the conflict between the aspirations of the social justice case and the business case. 'Pursuing equality' is one of seven values most frequently cited as of defining importance to people working in the UK voluntary sector (Blake et al., 2006); hence, such conflicting demands may be experienced as particularly destabilizing if they challenge the organization's overall sense of purpose or mission. We therefore regard diversity practitioners as located within the competing aspirations of the activist, who desires to challenge, resist and destabilize the 
status quo, and the manager who aims to 'introduc[e] order and co-ordinat[e] flows of things and people toward collective action' (Czarniawska Joerges and Wolff, 1991: 529) and towards organizational goals.

We chose an action research group as the vehicle for our enquiry because we sought to gain greater insight into the ways in which practitioners engaged with these competing tensions. In contrast to focus groups, the intention of action research is that the participants choose the topics for discussion, and they shape the direction of debate at least as much as do the facilitators. By working together on current issues and concerns, participants gain insights that may be beneficial to them in their organizational roles as well as generating data for researchers.

We sought to engage people who had a significant responsibility for implementing diversity strategies within their organizations. We publicized the opportunity to participate in our research study through voluntary sector networks. Participants were self-selecting and nine people responded positively to our invitation. We chose not to impose restrictions on job title or role and indeed participants occupied a range of positions (see Table 1).

The group ran for six months, during which the overall number of participants at each session varied significantly, although a core of four, consistent attenders - named here as Yinka, Corinna, Farah and Ruth - is clearly identifiable.

We developed a working pattern in which one member of the group would take up to 20 minutes presenting an issue of concern. The group members then discussed this issue, while the presenter initially remained silent, joining the conversation for a final reflection. Our 
intention was that this structure would create the possibility for dialogue, in the sense that Bohm (2008: 7) suggests, in which the group makes something 'in common'. This form of dialogue facilitates the occurrence of 'generative moments' (Carlsen and Dutton, 2011: 13) through which there is greater potential for the emergence of what Lawrence (2000: 12) describes as the 'unthought known ... that knowledge that can rarely be acknowledged through thinking'. We also considered that by reflecting on the dynamics within the group a more systemic analysis might be achieved than would have emerged from interviews. This was in keeping with our desire to surface some of the more contentious aspects of diversity management. We met before and after each session to reflect on the issues discussed and our experiences of the dynamics of the group. We kept our own notes, as well as recording (with the permission of the participants) and transcribing each session. After each session we produced a brief summary that we emailed to all the participants, asking for feedback and comments.

We saw our role as being primarily facilitative; however, we recognized that as the convenors of the group we framed the invitation to participate and provided the structures for engagement. These provided an implicit boundary around the material that could be brought and the responses that could be made. For example, in our reflections subsequent to each session, we felt that as we had not established the group as a therapeutic environment, nor framed it within a psychoanalytical context, we did not have permission to probe into the emotional experiences of participants within the group itself nor to provide psychoanalytically-determined interpretations of particular events. We were also aware that our own multiple identities (each of us is a white woman, older, employed in an elite position) were likely to influence the ways in which we responded (or failed to respond) to the dynamics within the group and the issues raised. We chose to manage these multiple 
interests by sharing responsibility for shaping the sessions, alternating between facilitator and observer roles.

We also made a deliberate decision to employ free association as a reflexive device, following Milner's (1987: xxi) proposition that when you let your mind roam freely 'there is no such thing as irrelevance ... whatever pops up is in some way important, however farfetched it may appear'. The images, metaphors and random thoughts that emerge in this way are, she suggests, 'symbol(s) for knowing' (Milner, cited by Letley, 2013: 84). Armstrong (2010), who has used free association in organizational consultancy, believes that the material generated, including that which is expressed in symbolic form, is not 'just' important to the individual knower, but that 'meaning . . . always emerges as a function of the relatedness between three parties; consultant, client and organisation-in-the-mind' (p. 103). We therefore regarded the associations generated within the boundaries of the project as 'belonging' to that relationship, and as indicators of important avenues for exploration.

As depicted earlier, the association of 'phantasmagoria' with the uncertainties and anxieties our diversity practitioners expressed indicated a promising avenue for investigation. We proceeded through extensive cycles of reflection and interpretation following successive research into the history and etymology of the phantasmagoria and its various appropriations as a metaphor, and the extent to which these multiple, overlapping and sometimes contradictory meanings helped us to make sense of our experiences in the group, and the issues raised by the participants. These cycles of reflection took place over many months; proceeding through joint discussions, re-readings of the transcripts and presentations of earlier drafts at conferences and seminars, which enabled us to construct the particular account of diversity management that we now present. 


\section{Shadow and light in diversity management}

As we reflected on what we saw through the analytical lens of the phantasmagoria, we noticed that our memories of the five sessions of the action research group had taken on something of the qualities of the phantasmagoria itself. The structure we had imposed for the recounting of issues created a momentum in which particular individuals and concerns seemed to loom large for a little while, occupy centre stage and then disappear back into the shadows. This apprehension of events was increased by the actual comings and goings of the participants, only two of whom attended all sessions. On two occasions participants joined who had not attended before, presented an issue that dominated the discussions, and then disappeared, one for good, another for many weeks. In our presentation we have tried to convey some sense of the way in which these discussions unfolded and, given that we can only present a small selection of the data generated throughout the sessions, have chosen to focus on the more unsettling moments, using these as opportunities for reflection and inquiry. Our adoption of the phantasmagoria metaphor guided the selection of the material we present below; thus, this account is itself an assemblage, or montage of events and exchanges, involving characters, stories, images that appear, reappear or are transformed. The organization of the material follows a chronological pattern but also presents a narrative in which participants' initial apprehensions of diversity management as something that was difficult to concretize are themselves super-naturalized and exposed through the descriptions of two more specific practice dilemmas that provoked feelings of fear, anxiety and helplessness. One of these practice dilemmas is very context specific, concerning the practices associated with collecting monitoring statistics, whereas the other concerns experiences of impotence and confusion when faced with instances of significant transgression. 


\section{$\underline{\text { Ambiguity and anxiety }}$}

We begin our account with the theme of ambiguity alongside the concomitant expressions of fear and anxiety that gave rise to the association of the phantasmagoria. The idea that there is something ambiguous and ill-defined about the diversity project emerged when John made the comment cited in the introduction: 'I'm not actually sure exactly what equality and diversity should look like for our organization', going on to ask 'what does it [managing diversity] actually look like in reality?'. He also raised the possibility that, as a consequence of this uncertainty: 'it might be that what we're doing is fine but we really don't know'. In the ensuing discussion the theme of ignorance was picked up by the other participants - thus Theresa commented: 'I think people don't understand what diversity management is, and it's [my job] to try to get the message across'. She went on to suggest that such ignorance and uncertainty were fairly universal phenomena: 'I talk to people from other organizations ... and they are more or less in the same situation as I am and nobody knows what to do now'. It is possible to discern two contrasting threads in Theresa's account - whether diversity management was something that she, as a diversity practitioner, largely understood but others in her organization did not, or whether it was inherently unknowable - thus rendering her task of 'getting the message across' an impossible one. As the main criterion for participation in the group was that of having significant responsibility for implementing diversity management initiatives, in our subsequent reflections we realized that we had made an implicit assumption that members would present themselves as being, overall, quite knowledgeable and confident. Instead (to our surprise) they presented themselves as relatively ignorant and in need of reassurance (that what they were doing was 'fine'). As the opening discussion progressed, participants shared the view that the uncertainty surrounding the practice of diversity management was associated with a notable degree of anxiety on the part of others in their organizations. This anxiety was, in turn, linked to their 
perception that these others found diversity to be difficult to speak about. For example, according to Corinna: 'they [other staff] don't feel free to talk about diversity and equality, they feel a bit anxious ... to speak up openly about issues around that and how it relates to their work'. Ruth concurred: 'I know in my organization people in more senior . . . they're frightened, you know'. Corinna agreed:

I think ... sometimes the biggest obstacle to addressing divisions or discrimination or whatever - it comes from fear . . . they don't want to say anything about it because they're afraid - it's this whole political correct thing where they don't want to offend or by bringing it up they don't know if they have the right words ... nobody wants to be seen as a bigot or be seen to be discriminatory.

In Corinna's comment 'political correctness' takes on spectral form, haunting these managers and frightening them into silence. Discussion within the group on the theme of politically correct language concerned the relationship between speaking correctly or incorrectly and internal beliefs - the view emerging from within the group that people should not be frightened of saying the 'wrong' thing because it was not necessarily evidence of bigotry or of holding the 'wrong' beliefs. These comments seemed to be aimed at diminishing the fear of the punishing power attached to the spectre of political correctness. However, the discussion of those in the organization who were regarded as recalcitrant, or as having difficulty in understanding or engaging with diversity, then took a rather different turn. John put forward the view that greater organizational commitment to diversity would be achieved by ensuring that only people with the 'right type' of attitudes were recruited. In the following exchange between John and Lorraine the ‘wrong' ideas were attached to older organizational members:

... you're dealing with people who, you know, a lot of our volunteers ... or, you know, of the older, you know sixty-plus. (Lorraine) 
... a bit more entrenched. (John)

... yes, so it's dealing with the people who've been here for many years . . . it's dealing with those people who've got those entrenched ideas. (Lorraine)

Frances, conscious during this interchange of her own membership in the 'sixty-plus' age group, and also of the questions raised about the 'right' kind of language, asked shortly after: I was just wondering whether if somebody said the wrong word - would we correct them? In this group, say I used a word you felt uncomfortable with - is it appropriate to say I'm not comfortable with that kind of language . . .?

Ruth responded straightaway: 'It's quite interesting isn't it, because I sat here listening to a conversation earlier . . . which was actually quite ageist and was sat here thinking should I say something?'.

Ruth's response unsettled the rather cosy consensus that it was only the 'others' that did not know how to engage correctly with diversity. Neither Lorraine nor John attended any further sessions and whether this uncomfortable interlude contributed to the cessation of their engagement is not known. However, in our subsequent reflections we noted that Lorraine had presented herself, in contrast to the others cited above, as feeling quite confident about her competence around diversity practice and wanting to share her expertise with the group. We speculate that in different ways both John and Lorraine may have been expecting both to give and receive greater certainties than were on offer. Rather than clarifying what diversity is and how to do it, the discussion had instead intensified its ambiguity. 
In summary: in the opening session participants represented organizational members (amongst whom they sometimes, but not always, included themselves) as being unable to act effectively on diversity because of its phantasmal qualities - it resists being captured or pinned down. As the discussion developed, the inability to act was attributed more specifically to its more fearful aspects - 'managers' (in particular) were scared, primarily of saying the 'wrong' thing. Discussion of these fears invoked 'political correctness' as a kind of vengeful spectre, the fear of which was capable of silencing or immobilizing organizational members - and thus exercising a malevolent rather than a benign, influence. However, the reaction to Lorraine's comment disrupted the reassuring idea that such fears were illusory as long as those in question were well-intentioned, because she appeared to be expressing her 'actual' beliefs about the over sixties as a group, rather than inadvertently using the wrong words.

\section{Super-naturalizing practice: Exploring resistance to diversity monitoring}

Participants' uncertainty about what diversity management 'really is' raised questions concerning what actual substance lay behind its presentation and appearance; whether its practice was primarily a matter of saying the 'right' things and avoiding saying the 'wrong'

things. In the second session, the focus of discussion shifted more directly to the practice of diversity management, specifically that of diversity monitoring - asking organizational members and clients to categorize themselves according to an established set of diversity markers. Diversity monitoring has become highly normalized within the UK, where it is regarded as being the foundational practice from which organization-specific strategies can be developed. Thus, Trevor Phillips, the ex-chair of the Equality and Human Rights Commission, recently castigated organizations for not having 'accurate figures on the level of ethnic minority employees', commenting that: 'you cannot have a strategy to deal with this 
[their under-representation in senior posts] if you don't understand the scale of the problem' (the Guardian, 11 September 2014). Interestingly, however, in many European countries diversity monitoring is not considered desirable or good practice. For example, there is considerable opposition to the practice in France, the Netherlands and Sweden (Wrench, 2007). In Germany, where 'there is no official data on discrimination in employment' (Carles et al., 2011: 2235), the collection of statistics recording ethnicity was illegal until recently (Simon, 2007), reflecting historical awareness of the potential for such information to be used for ill purpose.

Discussion of monitoring practice within the action research group revealed a tension between socio-demographic categories formulated as depersonalized and disembodied data to be collected for organizational purposes, and as descriptions of self and others over which it is possible to exercise choice and control. Thus, individuals might apply diversity markers to themselves in a way that enhances their sense of agency; but they might also find that the categories that others wish to impose upon them (even where the intention is benign) have effects that are more disempowering than empowering. Yinka's introduction to diversity monitoring in the housing charity where he worked reflected an understanding of the practice as strategically important:

... clearly one of the reasons for doing this is to identify any new trends, any issues that may arise for different types of clients, so that we can actually see if there's a need for action, if there's a problem somewhere in terms of potential discriminatory issues or - if some groups of people are missing out on a particular service that they should be getting - how do we engage, how do we actually improve that service to meet their needs? 
However, Yinka's dilemma was that, despite a coherent rationale for monitoring, the staff with responsibility for its implementation displayed a reluctance to ask for the information needed. He explained the basis for their resistance to the other participants: '[I]t can be intrusive, especially if you're asking about disability . . or sexual orientation or religion'.

Farah agreed: '[Y]ou're asking a member of staff to ask this person about their personal data - personal information - so they feel uncomfortable giving this person information about themselves and that person who's collecting the data feels uncomfortable about asking'. Following Yinka's and Farah's acknowledgement of staff unease about the process of collecting such personal information, Rosemary (attending her first and only session) raised questions about its reliability, especially when people were asked to fill the forms out themselves:

People put themselves down - black people put themselves down as white, white people put themselves down as black ... we've tried doing it and it worked to some extent but then there's the whole other extent to which it doesn't work.

But any assumptions that such behaviour is necessarily a product of carelessness, ignorance or deliberate provocation were disrupted when participants reflected on their own reactions to being asked for personal data. Yinka told us:

I might say [I am] black African . . . then I might say black British because I was actually born in this country, okay I moved out for a while and came back to the UK, and my children sometimes they actually go between black African and black British. 
Farah similarly admitted to a reluctance to label herself as 'BME' [Black and Minority Ethnic], a category widely used in the UK to encompass everyone outside a presumed but largely unexamined white majority:

Personally I found that I don't like being called, like BME what is that? That's not me and I can't identify with it, however I have a disability and I'll quite happily say I've got a disability because it's not obvious, and I like to raise awareness that disabilities aren't always visually there, so I'll quite happily tell people that I have a disability so yeah, it's kind of changing people's perception as well that leads me to give myself a label.

Rosemary's presentation of issues relevant to her advice-giving organization problematized this process of ascribing, or being ascribed a label, still further. Following Yinka, she had also chosen to concentrate on monitoring in the issue she presented for discussion. Her observation on the process again highlighted the tension between benign intentions in diversity management (in this case involving the increased organizational inclusion of those from disadvantaged groups) and less desirable outcomes. In discussing the questions asked by her organization of potential volunteers, she commented:

It's very detrimental to be having to keep defining yourself as a mental health service user - you're trying to not allow that category to exhaust your self-image and yet here you are pitching up at these organizations who repeatedly ask you whether you're a mental health service user! That's the one I find really difficult because it's having completely the opposite effect on the person as the object of the organization.

The way in which this discussion unfolded is interesting. Yinka began it by highlighting the reluctance of staff towards collecting the information necessary to sustain the practice of 
diversity monitoring. The cause of this unease is initially attributed to a perception that to ask for it is intrusive, that so doing involves crossing an intangible boundary between the personal and professional. Conventional UK diversity practice, which suggests that the collection of this information is unproblematic, necessitates that organizations apply the categories used to mark diversity as if they were stable and uncontested, as demonstrated by Trevor Phillips' comments cited above. These assumptions were disrupted in the discussion in the action research group, which suggested that the processes of data collection cannot be so easily objectified; the reluctance of employees can be understood as an acknowledgement of the personal costs involved to both worker and client.

So far in the discussion it is not the labels themselves that are being challenged, but the appropriateness of asking for the information. However, Yinka's and Farah's accounts of how they provided their own data led to a destabilizing of the labels themselves; while Rosemary's contribution demonstrated that having an unwanted label imposed on you can reinforce, rather than challenge, disadvantaged positioning. Critical diversity scholars have a long tradition of problematizing the processes and constructions of identity (see, for example, Prasad's 2012 discussion on the fluidity of sexual identity). However, the implications for practice are rarely acknowledged, so that although Farah resists applying the label 'BME' to herself she nevertheless referred at one point to a 'BME users' group' in her organization; thus demonstrating participants' struggle with the dehumanizing effects of these labels alongside the heroic power invested in their use to change attitudes and challenge discrimination. They acknowledge that individuals may feel haunted by an identity that they want to shake off (such as mental health service user) or want to be known by an aspect of their identity that is invisible to others (Farah's disability). These labels themselves exert a form of super-natural power but their use may reinforce marginalized positioning. Who has 
the power to deploy the labels and to what end is salient, and highly context specific. Deciding which categories to privilege for data-collection requires choices about which aspects of identity are regarded as important; they are elevated above other, less relevant or important characteristics. Mason (2003) points out that the categories chosen to differentiate ethnic origin in the UK are highly determined by its colonial heritage, with fine-tuned differentiations of 'Asian' identity deemed to capture people whose origins are in India, Bangladesh or Pakistan, but few, or no categories, for people originating in Korea, Japan or other equally 'Asian' countries.

However, interestingly, the categories that are privileged in monitoring practices are also the very aspects of identity that have traditionally been seen as undesirable within the work context; the disabled worker, who is seen as less productive, the older worker (holding the 'wrong' attitudes, as two of our early participants suggested), the emotional woman (Thanem, 2011) and the religious (whose commitments to work are diluted by loyalties beyond the organization; a point that is illustrated in the following section), or those such as the black slave or the colonial worker whose labour is essential but whose loyalty can also not be relied upon; these are the people who either cannot serve the capitalist project efficiently or whose allegiance to it is not complete. The very fetishizing of specific identity markers serves to mask, as Rosemary identifies, their complicity in marginalizing the 'monstrous' others (Thanem, 2011) who threaten the organization's boundaries. The practices of monitoring can thus be understood as phantasmagorical; they super-naturalize the ordinary, investing them with an uncanny power, but exposure reveals them as the shadows of haunted modernity (Warner, 2006). 


\section{$\underline{\text { Trickery and deception }}$}

The spectres of the phantasmagoria are illusory; the reality behind their appearances is that of artifice. Another aspect of the uncertainty that participants attached to diversity management concerned whether a convincing illusion of doing diversity could be manufactured without any fundamental changes having been made to organizational values and beliefs. This surfaced in the third session - following from a discussion concerning how far external benchmarking acted as a resource for achieving greater clarity about organizational performance in relation to diversity management. The quality framework developed by a voluntary organization advocating for the rights of sexual minorities was given as an example, with participants aware of several organizations (including several police authorities) that had recently been validated by the group for the quality of their work. However, Farah told us that she had once worked for one of the police authorities concerned, and:

We found that there was no real kind of evidence that they [the LGBT group] were checking that you were doing this; you could just tick that saying that you're doing this, and so I find that a lot of places might just be saying yeah, that sounds like something we're doing but - it's not being checked.

On the other hand, Yinka, who had worked for the same authority, suggested that their achievement was more likely to be the product of 'enforcement':

[T]hey have a zero tolerance on a lot of issues on equality, really quite draconian at times I've seen situations where members of staff have been actually sacked for just saying $\mathrm{x} y \mathrm{z}$ and so I think that's how they decided to go about it! [Laughter] 
This discussion highlighted the possibility that the appearance of successful diversity practice might be an illusion, or deceit, masking inaction (Farah) or coercion (Yinka). Furthermore, Yinka's observation again highlights the questions raised in the first session concerning what diversity management 'really' is, and the relationship between what people say and what they believe. Whereas in Yinka's story the actors involved said the 'right' things but without necessarily believing them, the final examples that we give here (taken from the fourth, penultimate session) encompassed accounts of organizational actors who said the 'wrong' things for questionable reasons. They involved the experiences of managers being challenged by others who made overt expressions of racism or homophobia, who did not seem to share the fear of not appearing politically correct, but who were themselves members of more marginalized or socially disadvantaged groups. Managers' uncertainty about how to react in these situations was again associated with the difficulty of separating reality from simulation - of knowing whether these were expressions of genuinely held beliefs, or deliberate provocation. In Ruth's case, the unwanted response arose in reaction to a diversity training session; which seemed to act as a catalyst in setting free transgressive beliefs that had previously been contained.

Ruth had re-joined the group in this session, having been absent since the first meeting. Her story concerned her experience of running diversity training sessions for her staff, after which participants were required to give their reflective comments. She told us about the reaction of some of her staff to a recent session on sexual orientation:

We have probably - I think it's 55\% of our staff come from ethnic minority groups mainly African - very, very high levels of religious belief whether that be Christianity or Islam . . . at the end of the sexual orientation training which looks at things like attitudes and language and milestones and how we support service users who are gay 
or lesbian or bisexual ... they do these reflections which they then send to me and I've had a number which have said actually I don't agree with anything you've been saying, this is what the Bible says ... I actually had an assignment which actually told me if I'd talked about the[se] things . . . in their country I wouldn't be on this land by now and basically telling me I would be shot ... I didn't take it as a threat but again quite shocked by the reaction and I'm sort of left there thinking what can I do?

Corinna's example concerned the way her organization had responded to the behaviour of a client who 'harassed a member of staff on several instances using homophobic and racist language'. She considered the response had been inadequate:

We're not taking this seriously because it was verbal, it wasn't a physical assault . . . he [the manager dealing with the incident] was like, 'oh let's just have a chat with the client and let him know that it's not appropriate', but not really taking any formal routes, and to me that is lip service, to me that doesn't show that we stand behind our staff . . . but we do need to have some sort of a ground to say what's acceptable and what's not acceptable, and even though we are working with a difficult client group I personally am not going to excuse or condone certain types of behaviour or language being used.

The possibility of deceit emerged in the discussion that followed in the question about whether such behaviour was deliberately provocative, with Ruth saying:

It's really difficult isn't it . . . there are some individuals that actually really do mean it when they say it - yeah? And there are some who don't - and they may not even know what they're saying other than they're looking for a reaction and it's how you differentiate between the two and then how are you seen to be being fair. 
Ruth and Corinna struggled to make sense of such expressions of homophobia and racism; whether they should be taken at face value, whether they are symptoms of an underlying malaise and whether it mattered if the comments were 'meant' or not. This latter point highlighted the possibility that not only might people say the 'right' thing, but not understand it or believe it, saying the 'wrong' thing might also be an illusion if the intention was merely to provoke. However, in presenting her account Ruth herself had said something which provoked a reaction from the group - even if this was not her intention. She had chosen to introduce the transgressive others in her story by reference to their ethnicity and this caused Yinka to seek reassurance that not all the African Christian staff had reacted in such an extreme way. He noted that she had mentioned other staff who had also voiced disagreement with the policy on sexual orientation yet who had claimed that, despite their personal views, they would not discriminate against LGBT people. However, she had not referred to this group of employees in terms of their ethnicity. He asked her: 'What I was wondering, you didn't mention what's the profile of that particular group? What's their profile?'.

After probing several times: 'I mean the ones who were able to sort of - agree with and that and stay on board ...?'?

Ruth replied that: '[Y]eah, no they were African - the majority of our staff actually come from Nigeria, Uganda, Zimbabwe, South Africa'.

Although Ruth's representation caused Yinka unease it served to problematize the boundary between the subjects of diversity initiatives and the staff who implement them, as well as that between those who are fearful of 'saying the wrong thing' and those who are not so afraid. Ruth's staff are from a UK minority ethnic group, a minority in terms of how they interpret 
their religious devotion and, given that they were care workers, they are also low waged. In Corinna's example, the transgressive client was homeless. In these accounts these characters have been rendered 'monstrous' and, as such, have caused the managers to become impotent; Corinna describes a manager who has failed to act effectively; Ruth says she does not know what to do even though the employees in question have clearly breached organizational codes of conduct.

From these accounts it would appear that the dilemmas discussed in the group lie at the interface between diversity as saying the right thing, as doing/practising the right thing and as believing the right thing. Our analysis suggests that diversity practitioners are located in a liminal space, between reality and illusion, with few fixed points of reference. Mainstream accounts of diversity management present its practice as relatively straightforward but the dilemmas discussed by the practitioners in our action research group challenged this assumption; they experienced doubts and confusion, which were, in turn, linked to an inability to act. Observed through the lens of phantasmagoria, these examples reveal the refusal of elements of diversity to be contained, controlled and neutralized - they become transformed instead into unpredictable, unreliable and even transgressive phenomena.

\section{Discussion: Diversity management as a gothic tale}

Our aim in this article has been to develop greater understanding of the emotional experiences that accompany the practice of diversity management; specifically those of confusion, anxiety and fear that emerged during the first and subsequent sessions of the action research group. The way in which participants represented diversity management triggered an association with the spectral qualities that are attached to the phenomena found in a phantasmagoria. Adopting the phantasmagoria as an analytical lens, we reviewed the 
material generated across the action research group meetings and considered ways in which aspects of it might be seen to possess, or take on such super-natural elements. Through this analysis we crafted an account of diversity management as a gothic tale, haunted by spectres and super-naturalized practices that give rise to fears and uncertainty. This representation leads us to suggest that the uncanny dimension of diversity management, the spirit that haunts this fundamentally modernist project, is that, in contrast to more mainstream accounts, its practice causes difficulties; people behave in difficult and unpredictable ways, benign actions produce malevolent results, things we try to make quantifiable escape from the efforts to control and bind them. Diversity attributes, rather than being controllable entities (Ahonen et al., 2014) appear to be changeable and unreliable; imbricated with power but also resonating with the ghosts of historical wrongs. A fear that haunts the possibility of facing these demonic aspects head on is that of opening Pandora's Box, releasing emotions and beliefs that may not be containable. These more fearful aspects of diversity management contribute to the sense that it is unknowable, that the reality is not necessarily that of the appearance. The implications of these inherent contradictions in the diversity project for the practitioners in our action research group were that they were unsure how to act.

Phantasmagoria are populated by a culturally familiar repertoire of frightening characters. Our analysis suggests several such spectres. The first of these is the spectre of political correctness, the fear of saying the 'wrong' thing. This fear was named in the action research group sessions and within the UK its salience has recently achieved concerning relevance, following an inquiry into the investigation of large-scale child sexual abuse in Rotherham, in which the offences were largely carried out by men of Pakistani heritage. Systemic failures to act, manifested across the entire range of professional services, were attributed by the Home Secretary to "institutionalized political correctness" [that] had contributed to the authorities 
turning a blind eye to the abuse of at least 1,400 children between 1997 to 2013' (the Guardian, 2 September 2014). However, in the aftermath of the inquiry, 'members of the British-Pakistani community' were quoted as condemning 'both the sexual abuse and that it had been covered up for fear of “giving oxygen” to racism' (BBC news, 27 August 2014: emphasis added). The Home Secretary's words draw on a familiar (in the UK) cultural tale, which has been taken up by right-wing commentators, in which cowardly individuals and agencies failed to act appropriately on instances of abuse because they feared being accused of being politically incorrect. These stories represent political correctness as a menace, preying on the susceptible and misguided. This account is problematic but powerful, as evident from the way our participants used the fear attached to being perceived to be politically incorrect to explain why management in their organizations failed to engage effectively with diversity management.

We suggest that at least two other culturally familiar spectres were invoked during the sessions: the aged sixty-plus with entrenched attitudes and the African Christian sexual bigot. These spectres were invoked through the eliding of disparate characteristics: age with entrenchment; Christian beliefs with African identity, producing expectations and assumptions of greater intolerance. Such elisions would not have been possible if these spectres were not already present within the social imaginary. Finally, we suggest two other spectres are those of the 'good person' - the 'super-human' practitioner who does not make mistakes - and the 'good organization' that is successful at managing diversity.

The spectre of the super-human practitioner may be of particular relevance to diversity practitioners working in the context of the UK voluntary sector, whose role may be inherently contradictory. The practitioners in our group could identify with the subjects of the diversity 
initiatives, as evident in the examples given here where they drew on their own ethnicity or disability. Yet, practitioners are not activists; they are embedded within systems and structures designed to serve the interests of the organization. Their role is more akin to Meyerson's (2003) 'tempered radicals'; not wholly compliant but neither always able to take up a position of direct challenge. However, if not directly challenging, participants did perceive their role as that of providing constant explanations of the importance and relevance of diversity practices. Despite the inherent difficulties in applying business case logics and rationales to the voluntary sector, practitioners nonetheless often appealed to these logics in framing their arguments.

Given the importance of social justice to their organizations, it might be expected that our participants would experience less resistance and difficulty in getting other organizational members to engage than might be the case in for-profit organizations, yet the experiences they recounted suggest otherwise. We speculate that such organizations may be more, rather than less, challenged by diversity and its associations, not only because it has become so highly politicized but also because of the competing interests found amongst the different stakeholders whose diversity they are expected to manage. Ruth and Corinna's examples provide some evidence to support this proposition.

These elements (of increasing politicization and conflicting stakeholder interests) are not necessarily unique to organizations in the UK voluntary sector. In reflecting on the wider implications of our findings, we propose that further consideration of the phantasmagoria suggests some possibilities for alternative ways of doing diversity. First, we observe that Farah, and, to a lesser extent Yinka, in their selective deployment of identity markers, were practicing what Spivak (1993: 3) terms 'strategic essentialism', with Farah making a 
deliberate, political choice to deploy her identity as disabled in order to raise awareness. Spivak's initial championing of essentialism as a strategic choice is dependent on actors retaining a conscious awareness of the contested and fluid nature of such labels while simultaneously acknowledging that they are weapons to be deployed in the service of particular goals and aspirations. Thus, strategic essentialism requires the fetishizing of the value of certain practices in achieving specific aims in concert with an awareness of the ephemeral and relative nature of that value. This might be described as a sort of double turn a super-naturalizing of a practice while simultaneously de-naturalizing it; or, as Robertson intended, creating a ghost while jointly exposing the mechanism by which it is made. Etienne-Gaspard Robertson's phantasmagoria was designed to frighten and to reassure: exposing the mechanisms that created phantasms was intended to render them powerless. Applied to the spectres of diversity management this act of exposure might also depend on a double turn; an acknowledgement of their power to frighten alongside a process of realitytesting (as the term is used in psychotherapy); subjecting these spectres and ghostly manifestations to a process of reflection, probing them to investigate further the 'reality' behind the appearance. How might this be done? We noticed that possibilities seemed to open up in the action research sessions when unease was experienced, or at least acknowledged within the group. We therefore suggest that attending to the moments of unease, the perceptions of the uncanny as they unfold, may allow for context specific responses, transformative possibilities for action. If we apply this suggestion to the moments of unease we have recounted here (the 'wrong' use of the phrase sixty-plus; the reported unease of staff being asked to collect 'intrusive' monitoring data, Yinka challenging Ruth's reference to staff by their ethnicity) we can see that this might be the case. We might have handled the first session slightly differently as facilitators, perhaps by naming the unease, exposing its power to paralyze, presenting it as a topic in its own right for discussion and analysis within the 
group. Yinka's account of staff reluctance allowed the contradictions inherent in monitoring practices to be surfaced and reflected upon; Yinka's response to Ruth created the space for a separation to be made between the words, intentions and social position of the care workers whose anger and bigoted words had rendered her uncertain and unable to act.

By focusing on moments of unease and examining the elements involved through the lens of the phantasmagoria, our account of diversity management as a gothic tale reinforces the view that formulaic quick fixes or good practice recipes have only limited value in dealing with complex dilemmas. Instead, what was involved in these discussions was not only the repoliticizing of elements that mainstream accounts try to de-politicize, but, when participants owned the issues for themselves, it re-personalized elements that had hitherto been depersonalized. These processes were associated with unease and yet they suggest that diversity practitioners must necessarily engage with the emotional dimension of diversity in order to move forward. Furthermore, such emotions should not be regarded in negative terms but as generative moments within which we may find possibilities for transformation.

\section{Concluding remarks}

This analysis of our action research group's representations of diversity management is built on the foundation laid, firstly by the association of their comments to the phantasmagoria, and then, by conscious adoption of the phantasmagoria as our metaphoric, analytical lens. The tale we told is itself a phantasmagoria; it is a montage of selected events that necessarily omits many others. Our analysis has drawn on the original meaning of the phantasmagoria and the intentions of its earliest progenitor alongside later accretions of symbolic meaning derived from its appropriation as a metaphor; specifically its use as a means of critiquing capitalism more generally and the fetishizing of commodities. The account of diversity 
management that has emerged, thus builds on the recent use of gothic tropes in organization studies (Riach and Kelly, 2013; Thanem, 2006, 2011). The gothic, whether manifested in art, architecture or literature, represents the failure of the 'ceaseless quest to dominate nature which has long taken centre stage in the collective psyche of capitalist societies' (Harvey, 2010, cited by Burnett, 2013: 4). Applied to the analysis of organizational processes, it 'remind[s] us that organizations are not only the sites for mistakes or accidental disasters, but that they also have dark sides that nurture deliberate corruption, misconduct and dishonesty' (Riach and Kelly, 2013: 5). Our account highlights the dilemmas faced by practitioners who position themselves as strong advocates for social justice, as they struggle with the inherent contradictions of diversity management.

However, we are aware that our account is very partial. We note Oswick et al.'s (2002) caution about presenting metaphorical analyses only in terms of the similarities between the metaphor and the focus of analysis. The metaphor of the phantasmagoria highlights the shadow side of diversity management, not its successes; its contradictions and ambiguities rather than its strong value base; the experiences of unease, anxiety, discomfort and fear rather than those of pride, achievement and joy. We recognize that the format of the action research group contributed to producing these observations. Perhaps reflecting our own, more critical orientation, from the outset of the project we were more interested in hearing participants' dilemmas than in encouraging them to share good practice. Commenting more generally, Cassell and Johnson (2006) suggest that action research groups have the potential to unsettle dominant discourses and, thus, to provide a site for ambivalence and resistance, and in this we concur. However, we note that many models of action research are more action and solution orientated. The structure of the group may have served 
to increase participants' awareness of what they did not know, since groups, perhaps particularly groups of 'experts', can be perceived as inhibiting as well as nurturing.

The phantasmagoria emerges out of the conflict between the ideals of the enlightenment and the 'magic' of theocracy, thus providing a site from which the imposition of modernity more generally and, in Benjamin's examples, capitalism and the fetishizing of commodity more specifically, can be examined, exposed and critiqued. Diversity management is also a product of this context. In contrast with the aspirations of 'equal opportunities', which valorizes social justice, mainstream accounts of diversity draw on the fetishizing of economy, efficiency and rationality. Our practitioners are located within these competing understandings of diversity management. Both are, arguably, idealized and unrealistic, while the practice of diversity management is often experienced as muddled and messy. It is this muddle and confusion, the detritus of the modernist project, which gives rise to diversity management's phantasmagorical qualities.

\section{References}

Ahonen, P, Tienari, J, Merilainen, S, Pullen, A (2014) Hidden contexts and invisible power relations: A Foucauldian reading of diversity research. Human Relations 67(3): 263-286. Armstrong, D (2010) Meaning found and meaning lost. Organisational and Social Dynamics 10(1): 99-117.

BBC news (2014) Real or imagined: Racism 'fear' over Rotherham child abuse, (Katie Hall). URL http://www.bbc.co.uk/news/uk-england-south-yorkshire-28951612

Bendl, R, Fleischmann, A, Walenta, C (2008) Diversity management discourse meets queer theory. Gender in Management: An International Journal 23(6): 382-394. 
Benjamin, W (2002) The Arcades Project (trans. Eiland, H, McLaughlin, K). Cambridge, MA and London: Belknap Press of Harvard University Press.

Blake, G, Robinson, D, Smerdon, M (2006) Living Values: A Report Encouraging

Boldness in Third Sector Organizations. London: Community Links, Newham.

Bohm, D (2008) On Dialogue. London: Routledge.

Burnett, A (2013) The annihilation of space through time: Virtual organization as messianic call in catastrophic times. Paper presented to the 8th International Conference in Critical Management Studies, 10-12 July.

Cairns, B, Hutchison, R, Aiken, M (2010) It's not what we do but how we do it: Managing the tension between service delivery and advocacy. Voluntary Sector Review 1(2): 193208.

Calàs, M, Holgerssonn, C, Smircich, L (2009) Diversity management? Translation? Travel? Scandinavian Journal of Management 25(4): 349-351.

Carles, I, Howard, E, Kofman, E (2011) Gendered experiences of racial discrimination: Comparative socio-legal research. In: Schiek, D, Lawson, A (eds) European Union NonDiscrimination Law and Intersectionality: Investigating the Triangle of Racism, Gender and Disability Discrimination. Farnham: Ashgate, 2227-2240.

Carlsen, A, Dutton, JE (2011) Introduction. In: Carlsen, A, Dutton, JE (eds) Research Alive: Exploring Generative Moments in Doing Qualitative Research. Copenhagen: Liber: Copenhagen Business School Press, 11-24.

Cassell, C, Johnson, P (2006) Action research: Explaining the diversity. Human Relations 59(6): 783-814. 
Cohen, M (1989) Walter Benjamin's phantasmagoria. New German Critique 48(Autumn): 87-107.

Cox, TH, Blake, S (1991) Managing cultural diversity: Implications for organizational competitiveness. Academy of Management Executive 5(3): 45-56.

Czarniawska, JB, Wolff, R (1991) Leaders, managers, entrepreneurs: On and off the organizational stage. Organization Studies 12(4): 529-546.

De Cock, C, Baker, M, Volkmann, C (2011) Financial phantasmagoria: Corporate imagework in times of crisis. Organization 18(2): 153-172.

Dick, P, Cassell, C (2002) Barriers to managing diversity in a UK constabulary. Journal of Management Studies 39(7): 953-976.

Eiland, H, McLaughlin, L (2002) Translator's foreword. In: Benjamin W The Arcades Project, trans. Eiland, H, McLaughlin, K. Cambridge, MA and London: Belknap Press of Harvard University Press: ix-xiv.

Gabriel, Y (2005) The unmanaged organization: Stories, fantasies and subjectivity. Organization 12(1): 9-27.

Ghorashi, H, Sabelis, I (2013) Juggling difference and sameness: Rethinking strategies for diversity in organizations. Scandinavian Journal of Management 29(1): 78-86.

The Guardian (2014) May blames ‘institutional political correctness' for Rotherham scandal, 2September 2014.

The Guardian (2014) Public sector 'lacks diversity despite obligation to promote equality', 11September 2014.

Holvino, E, Kamp, A (2009) Diversity management: Are we moving in the right direction? Reflections from both sides of the North Atlantic. Scandinavian Journal of Management 25(4): 349-403. 
Janssens, M, Zanoni, P (2005) Managing diversity for many services: Theorizing diversity (management) in service companies. Human Relations 58(3): 311-340.

Janssens, M, Zanoni, P (2014) Alternative diversity management: Organizational practices fostering ethnic equality at work. Scandinavian Journal of Management 30(3): 317-331.

Kandola, P, Fullerton, J (2003) Diversity in Action: Managing the Mosaic. London: CIPD.

Lawrence, WG (2000) Tongued With Fire: Groups in Experience. London: Karnac.

Leslie, E (n.d.) Walter Benjamin's Arcades Project. Available

at http://www.militantesthetix.co.uk/waltbenj/yarcades.html (accessed 14 March 2012).

Letley, E (2013) Marion Milner: A Life. London: Routledge.

Litvin, D (1997) The discourse of diversity: From biology to management. Organization 4(2): 187-209.

Lorbiecki, A, Jack, G (2000) Critical turns in the evolution of diversity management.

British Journal of Management 11(suppl. 1): s17-s31.

Mason, D (2003) Explaining Ethnic Differences: Changing Patterns of Disadvantage in Britain. Bristol: Policy Press.

Meyer, M, Buber, R, Aghhamanoukjan, A (2013) In search of legitimacy: Managerialism and legitimation in civil society organizations. Voluntas 24(1): 167-193.

Meyerson, D (2003) Tempered Radicals: How Everyday Leaders Inspire Change at Work. Boston, MA: Harvard Business School Press.

Milner, M (1987) An Experiment in Leisure. London: Virago.

Oswick, C, Keenoy, T, Grant, D (2002) Metaphor and analogical reasoning in organization theory: Beyond orthodoxy. Academy of Management Review 27(2): 294-303. 
Özbilgin, M, Tati, A, Ipek, G, Sameer, M (2014) The Business Case for

Diversity. London: ACCA.

Parker, M (2005) Organisational gothic. Culture and Organization 11(3): 153-166.

Prasad, A (2012) Beyond analytical dichotomies. Human Relations 65(5): 567-595.

Riach, K, Kelly, S (2013) The need for fresh blood: Understanding organizational age.

Inequality through a vampiric lens. Organization. DOI: $10.1177 / 1350508413508999$.

Schwabenland, C (2012) Metaphor and Dialectic in Managing

Diversity. Houndsmills: Palgrave.

Simon, P (2007) 'Ethnic' Statistics and Data Protection in the Council of Europe

Countries. Strasbourg: European Commission Against Racism and Intolerance (ECRI).

Sinclair, A (2006) Critical diversity management practice in Australia: Romanced or coopted? In: Konrad, A, Prasad, P, Pringle, J (eds) Handbook of Workplace

Diversity. London: SAGE, 531-539.

Smith, A, Wallace, P (2004) The female gothic then and now. Gothic Studies 6(1): 1-7.

Spivak, GC (1993) Outside in the Teaching Machine. New York: Routledge.

Tatli, A (2011) A multi-layered exploration of the diversity management field: Diversity discourses, practices and practitioners in the UK. British Journal of Management 22(2): 238-253.

Thanem, T (2006) Living on the edge: Towards a monstrous organization theory. Organization 13(2): 163-193.

Thanem, T (2011) The Monstrous Organization. Cheltenham: Edward Elgar. 
Tomlinson, F, Schwabenland, C (2010) Reconciling competing discourses of diversity? The UK non-profit sector between social justice and the business case. Organization 17(1): 101121.

Warner, M (2006) Phantasmagoria: Spirit Vision, Metaphors and Media into the Twentyfirst Century. Oxford: Oxford University Press.

Wrench, J (2005) Diversity management can be bad for you. Race and Class 46(3): 73-84.

Wrench, J (2007) Diversity Management and DiSrimination: Immigrants and Ethnic Minorities in the EU. Aldershot: Ashgate.

Zanoni, P, Janssens, M, Benschop, Y, Nkomo, S (2010) Unpacking diversity, grasping inequality: Rethinking difference through critical perspectives. Organization 17(1): 9-29. 
Table 1 Action learning group participants (in order of appearance in this article)

\begin{tabular}{|l|l|l|}
\hline Pseudonym & Role and organisation & Sessions attended \\
\hline Lorraine & $\begin{array}{l}\text { Diversity and equality specialist: national } \\
\text { organization providing infrastructure support } \\
\text { to local volunteering groups }\end{array}$ & 1 st only \\
\hline Farah* & $\begin{array}{l}\text { Diversity and equality specialist: national } \\
\text { charity providing support for people with } \\
\text { cancer }\end{array}$ & 5 \\
\hline John & $\begin{array}{l}\text { HR manager: locally based educational charity } \\
\text { working with parents }\end{array}$ & 1 st only \\
\hline Ruth* & $\begin{array}{l}\text { Chief executive officer: regional service } \\
\text { providing housing and support for people with } \\
\text { learning difficulties }\end{array}$ & 3 \\
\hline Corinna* & $\begin{array}{l}\text { Diversity and equality specialist: large, city- } \\
\text { based, homelessness charity }\end{array}$ & 5 \\
\hline Yinka* & $\begin{array}{l}\text { Diversity and equality specialist: national } \\
\text { housing charity }\end{array}$ & 4 \\
\hline Rosemary & $\begin{array}{l}\text { Project manager: local, semi-autonomous } \\
\text { branch of a national advice agency }\end{array}$ & 2 nd only \\
support organization & $\begin{array}{l}\text { Project manager: locally based organisation } \\
\text { working with long-term unemployed }\end{array}$ & $2 \mathrm{nd}$ only \\
\hline Mike & $\begin{array}{l}\text { Project manager: locally based infrastructure } \\
\text { shera }\end{array}$ & 1 st only \\
\hline
\end{tabular}

*Core participant 